\title{
Dermoid Cyst of the Floor of the Mouth
}

\author{
Jessica R. Dillon • Andrew J. Avillo • \\ Brenda L. Nelson
}

Received: 1 October 2014/ Accepted: 17 October 2014/Published online: 29 October 2014

(C) Springer Science+Business Media New York (outside the USA) 2014

\begin{abstract}
A case of a dermoid cyst of the floor of mouth affecting a 19 years old male will be discussed. The macroscopic and histologic findings used for diagnosis will be covered. The typical features of this type of cyst will also be reviewed including radiographic and histologic findings. Discussion will include etiology and usual presentation, as well as treatment.
\end{abstract}

Keywords Dermoid cyst · Floor of mouth · Sublingual · Histology

\section{History}

A 19-year-old male presented to the dental clinic for a routine dental examination. During the head and neck exam, a fullness of the floor of the mouth was noticed. Upon questioning the patient he stated he was unaware of

Disclaimer: The opinions and assertions expressed herein are those of the author and are not to be construed as official or representing the views of the Department of the Navy or the Department of Defense.

J. R. Dillon $(\varangle) \cdot$ A. J. Avillo · B. L. Nelson

Department of General Dentistry, 1st Dental Battalion Naval

Dental Center, Building 22190, Camp Pendleton,

CA 92055, USA

e-mail: jessica.ruth.dillon@gmail.com

J. R. Dillon · A. J. Avillo · B. L. Nelson

Department of Hospital Dentistry, Naval Medical Center San

Diego, San Diego, CA, USA

J. R. Dillon · A. J. Avillo · B. L. Nelson

Department of Anatomic Pathology, Naval Medical Center San

Diego, San Diego, CA, USA any changes and he denied a history of recent trauma or infection.

\section{Radiographic Features}

Computed tomography (CT) images of the head demonstrated a well-circumscribed cystic lesion originating in the right sublingual region and spreading in a posterior direction. Multiple stippled calcifications could be seen in an otherwise heterogenous background (Figs. 1,2). There was no evidence of surrounding inflammatory changes or nodularity associated with the lesion.

\section{Diagnosis}

The lesion was removed by an intraoral approach. Macroscopically, the lesion appeared encapsulated; the cut surface revealed soft, yellow material (Fig. 3). Histological evaluation showed a cystic space lined by orthokeratinized stratified squamous epithelium, with a prominent granular cell layer. Within the cystic space was dense keratotic debris with focal calcifications. Underlying the cystic epithelium was fibrous connective tissue containing numerous sebaceous glands (Fig. 4).

The histologic differential diagnosis included the teratoma-like spectrum of cysts found in the cervicofacial region: epidermoid, dermoid, and teratoid. The epidermoid type has a fibrous wall without adnexal structures and is lined with flattened squamous epithelium. Dermoid cysts have a fibrous wall containing one or more secondary skin structures. The epithelial lining for the teratoid type ranges from simple stratified squamous epithelium to respiratory epithelium and has a wall containing secondary skin 


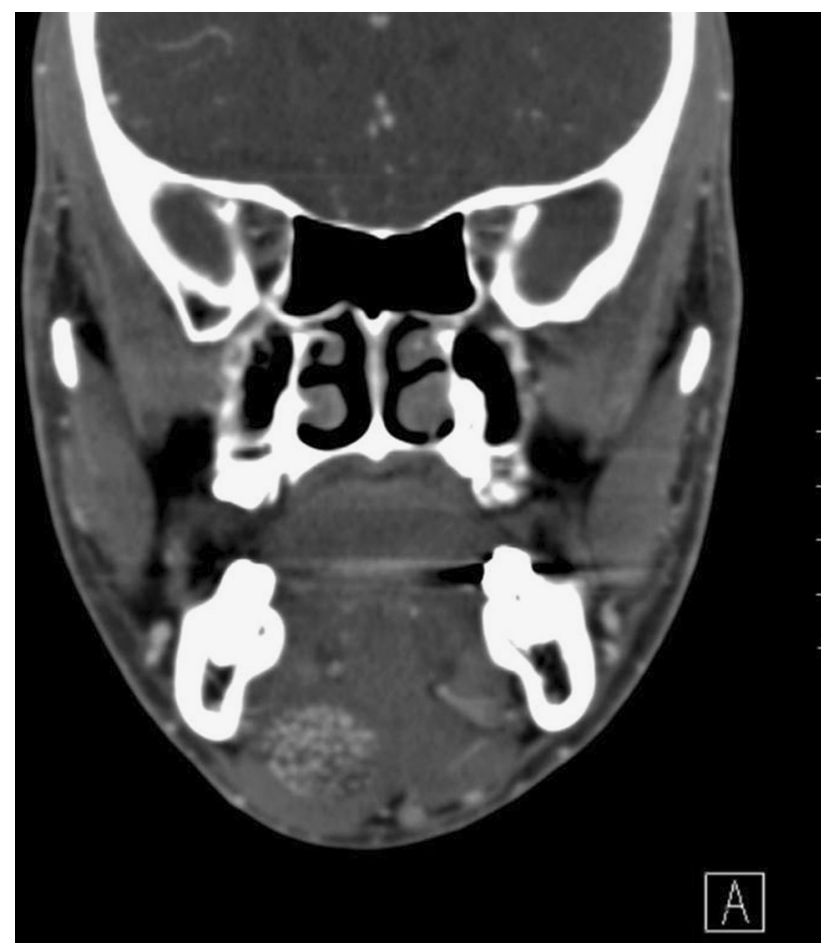

Fig. 1 Coronal computed tomography (CT) reveals a well-circumscribed mass within the right sublingual space. Multiple stippled calcifications can be seen in an otherwise heterogenous background

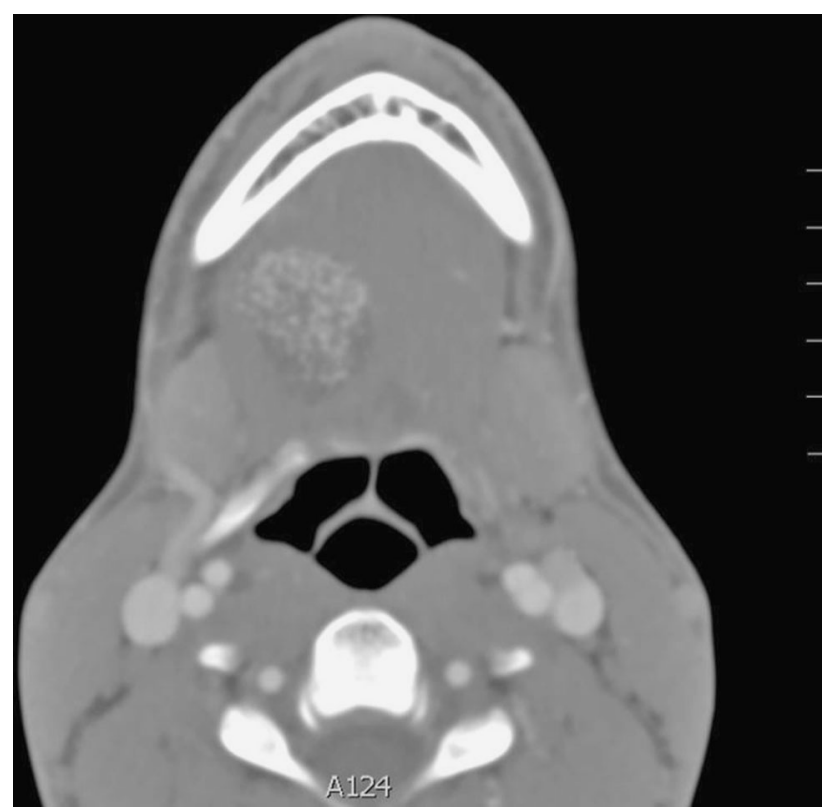

Fig. 2 Axial CT shows the mass slightly off the midline

structures and other structures such as muscle, vascular channels, and fat tissue [1]. The lesion was diagnosed as a dermoid cyst.

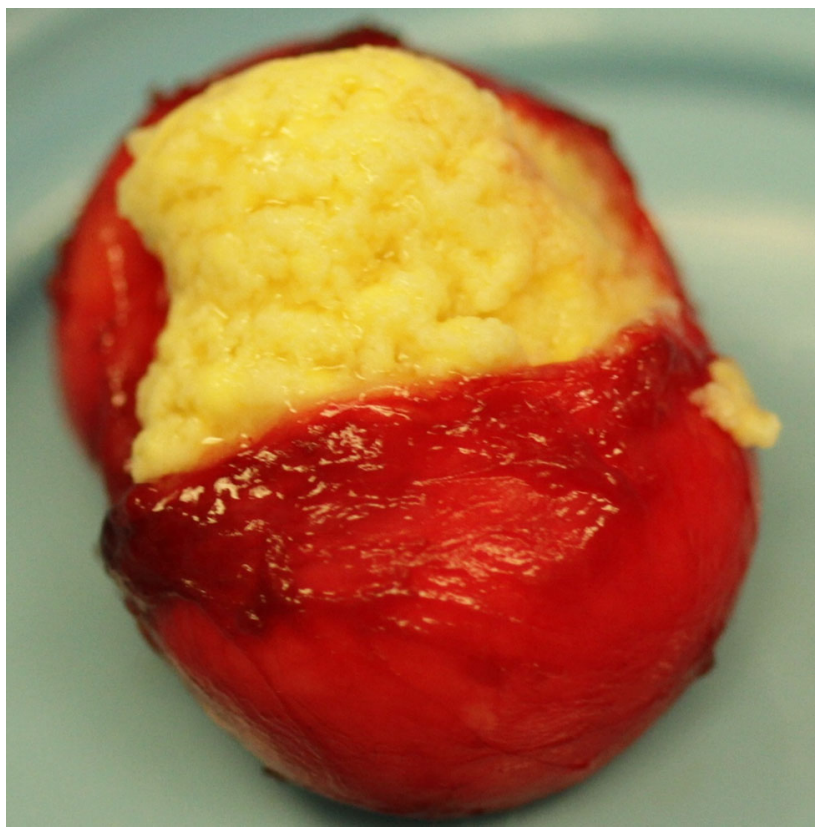

Fig. 3 Gross image shows a sack like structure filled with yellow keratin debris

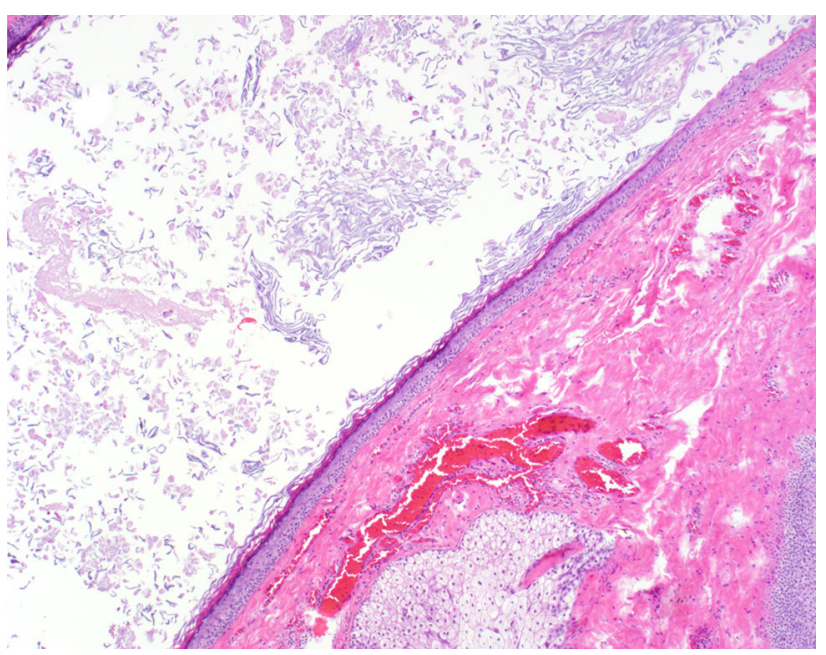

Fig. 4 A medium power photomicrograph shows an epithelial lined space overlying a fibrous connective tissue wall. The epithelium is stratified squamous with a definitive granular layer. Desquamated keratin is noted and a sebaceous gland is identified within the wall

\section{Discussion}

Dermoid cysts are a developmental cyst lined by epidermis-like epithelium and contain dermal adnexal structures such as sebaceous glands, hair follicles, or sweat glands in the cyst wall. They can be generally classified as a benign cystic form of a teratoma but do not contain tissue from all three germ layers and are therefore not true teratomas [2]. 
Etiologically, dermoid cysts may be congenital or acquired. The congenital type found in the cervicofacial region is derived from entrapment of epithelial cells during midline fusion in embryonic development. Acquired forms develop from traumatic or iatrogenic implantation of epithelial cells into surrounding tissues [3]. Not uncommonly found in the head and neck, almost seven percent of dermoid cysts in this region are located in the floor of the mouth [4]. While dermoid cysts can be seen at virtually any age, the highest incidence occurs in patients between 15 and 35 years of age, with no gender predilection [5, 6]. Dermoid cysts usually develop insidiously with patients not becoming aware of their presence until they are large enough to interfere with eating, speaking or swallowing [2].

Depending on the anatomic location of the cyst and the muscles of the floor of the mouth, dermoid cysts may be defined as sublingual or submental [7]. A sublingual cyst is located above the geniohyoid muscle and swelling with displacement of the tongue may occur. In cases that develop below the geniohyoid, a submental swelling with a "double chin" appearance may occur [2]. Because these lesions may also become secondarily infected and in rare cases may undergo a malignant change, they are indicated for removal [2].
The only effective treatment of dermoid cysts is surgical removal with complete enucleation. Treatment for a small cyst above the geniohyoid muscle may be possible through an intraoral approach and those occurring below the muscle may require an extraoral approach. Recurrence and malignant transformation to squamous cell carcinoma are rare [2].

\section{References}

1. Fulcher CL, Green HG, Green GH. Dermoid cyst. Oral Surg Oral Med Oral Pathol. 1966;22:127-31.

2. Neville BW, Damm DD, Allen CM, Bouquot JE. Oral and maxillofacial pathology. 3rd ed. St. Louis: Saunders Elsevier; 2009. p. 33-5.

3. Erich JB. Sebaceous, mucous, dermoid and epidermoid cysts. Am J Surg. 1940;50:672.

4. Taylor BW, Erich JB, Dockerty MB. Dermoids of the head and neck. Minn Med. 1966;49:1535-40.

5. Meyer I. Dermoid cysts (dermoids) of the floor of the mouth. Oral Surg Oral Med Oral Pathol. 1955;8:1149-64.

6. King RC, Smith BR, Burk JL. Dermoid cyst of the floor of the mouth. Oral Surg Oral Med Oral Pathol. 1994;78:567-76.

7. Di Francesco A, Chiapasco M, Biglioli F, Ancona D. Intraoral approach to large dermoid cysts of the floor of the mouth: a technical note. Int J Oral Maxillofac Surg. 1995;24:233-5. 